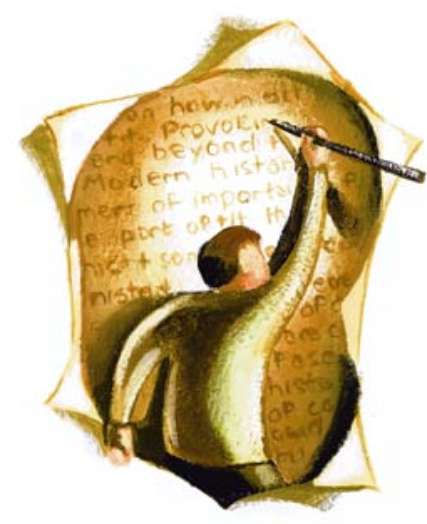

Risks on the roads

In a recent article about global trends in injury, ${ }^{1}$ Sally Murray describes prevention efforts for traffic-related injuries, but 2 independent trends in the developed world may reverse some of the improvements that have already been made: the aging of the population and the increase in the use of sport utility vehicles (SUVs)..$^{2,3}$ Despite improvements to newer passenger vehicles to reduce the effect of collisions with larger vehicles, including SUVs, concern persists regarding the greater risk of injury to the drivers and occupants of passenger vehicles and to pedestrians during collisions between vehicles of differing size and mass ${ }^{4,5}$ (these factors being the chief determinants in severity of injuries).

In the United States, $40 \%$ of new vehicles purchased are classified as light trucks or vans, many of which are SUVs. The preference for an SUV is shaped not only by individual choice but also by environmental influences, including economic and social factors. ${ }^{6}$ SUVs, some of which are marketed and purchased for their perceived safety image, are suggested to offer robust protection for child occupants. However, a recent study showed that despite greater vehicle weight, aggressive vehicle design and size of SUVs, the safety benefits for child occupants are similar to those offered by small vehicles. ${ }^{7}$ Given that motor vehicle crashes remain the leading cause of death and acquired disability in children, ${ }^{8}$ these data are troubling at best. SUVs also have the highest death rate for their own occupants of any broad class of vehicles, mainly because of high rollover rates.

Traffic safety literature indicates that SUVs and trucks inflict substantial external safety costs when involved in a collision, causing damage to other vehicles, road infrastructure, roadside objects and vulnerable road users. ${ }^{3,6,7,9}$ In particular, the risk of injury is an important deterrent to walking and cycling. In the United Kingdom, cycling accounted for nearly $25 \%$ of all road traffic in $195 \mathrm{I}$, but by 1994 this figure had fallen to just I $\%{ }^{10}$ The number of miles walked also declined, on average, by $17 \%$ between I $975 / 76$ and $1994 .{ }^{10}$ In a recent study that explored why children don't walk to school more often, $40 \%$ of parents reported traffic danger as one of several factors. ${ }^{11}$ If traffic danger continues to discourage people of all ages from walking and cycling, the disease burden related to inactivity will increase.

\section{Ediriweera Desapriya}

Department of Pediatrics

Centre for Community Child Health

Research

Vancouver, BC

Ian Pike

Director

Pamela Joshi

Research Assistant

BC Injury Research and Prevention

Unit

Vancouver, BC

\section{REFERENCES}

I. Murray S. Global injury and violence. $C M A J$ 2006;174(5):620-I.

2. Simms C, O'Neill D. Sports utility vehicles and older pedestrians: a damaging collision. Inj Prev 2006;12:6-7

3. Desapriya EB, Chipman M, Joshi P, et al. The risk of injury and vehicle damage in vehicle mismatched crashes. Int J Inj Contr Saf Promot 2005; I2:I9I-2.

4. World report on road traffic injury prevention 2004. Geneva: World Health Organization; 2004.

5. Desapriya EB, Pike I, Kinney J. The risk of injury and vehicle damage severity in vehicle mismatched side impact crashes in British Columbia. Int Assoc Traffic Saf Sci Res 2005;29:60-6.

6. Acierno S, Kaufman R, Rivara FP, et al. Vehicle mismatch: injury patterns and severity. Accid Anal Prev 2004;36:76I-72.

7. Daly L, Kallan MJ, Arbogast B, et al. Risk of injury to child passengers in sport utility vehicles. Pediatrics 2006;117:9-I4.

8. Soubhi H, Raina P, Kohen D. Neighborhood, fam- ily, and child predictors of childhood injury in Canada. Am J Health Behav 2004;28(5):397-409.

9. Crandall JR, Bhalla KS, Madeley NJ. Designing road vehicles for pedestrian protection. BMJ 2002; 324:II $45-8$.

Io. Road transport and health. London (UK): British Medical Association; 1997.

II. Centers for Disease Control and Prevention. Barriers to children walking and biking to school United States, I999. MMWR Morb Mortal Wkly Rep 2002;5I(32):70I-4.

DOI:I0.1503/cmaj.1060073

Sally Murray's article on rates of global injury and violence ${ }^{1}$ highlights the role of traffic-related injury and death. In discussions of traffic injuries, there is a tendency to use SUVs as scapegoats for increased risk to other road users and pedestrians because of incompatibilities between SUVs and other vehicles in terms of height, weight and frame geometry. This heightened risk is well known and is of even greater magnitude for full-sized trucks and vans. ${ }^{2,3}$

However, a rapid evolution is under way in the design of SUVs, from obsolete body-on-frame construction to unibody designs, resulting in benefits to occupants in handling and ride quality. It is likely that these new designs also decrease the risk to other road users, although perhaps unintentionally.

Until the recent arrival of the Honda Ridgeline, no light trucks have used unibody technology. All other vehicles in the light-truck category retain conventional body-on-frame designs, which align stiff longitudinal steel members with the head and upper torso of car occupants. This design, in combination with non-independent rear suspension, a recent trend to increasing frame height and the attraction that light trucks hold for aggressive young male drivers, renders these vehicles lethal.

Currently, collision data are assembled by lumping data for disparate frame designs into categories that describe external appearance better than internal construction. Much research remains to be done before the effect of frame construction can be quantified. ${ }^{4}$

Wider recognition of the relative risks posed by specific vehicles and frame types to other vehicles, cyclists 